Sensors 2007, 7, 1-15

sensors

ISSN 1424-8220

(C) 2007 by MDPI

http://www.mdpi.org/sensors

Full Paper

\title{
Determination of Critical Conditions for the Formation of Electrodeposited Copper Structures Suitable for Electrodes in Electrochemical Devices
}

Nebojsa D. Nikolic ${ }^{1} *$ Konstantin I. Popov ${ }^{1,2}$, Ljubica J. Pavlovic ${ }^{1}$ and Miomir G. Pavlovic ${ }^{1}$

1 ICTM - Institute of Electrochemistry, University of Belgrade, Njegoseva 12, P.O.B. 473, 11001

Belgrade, Serbia. E-mails: K. I. Popov: kosta@tmf.bg.ac.yu; Lj. J. Pavlovic: mikicar@net.yu; M. G. Pavlovic:duki@tmf.bg.ac.yu.

2 Faculty of Technology and Metallurgy, University of Belgrade, Karnegijeva 4, P.O.B. 3503, 11001 Belgrade, Serbia.

*Author to whom correspondence should be addressed. E-mail: nnikolic@tmf.bg.ac.yu

Received: 27 October 2006; in revised form: 12 December 2006 / Accepted: 15 December 2006 /

Published: 1 January 2007

\begin{abstract}
Electrodeposition of copper from acid sulfate solutions at overpotentials on the plateau of the limiting diffusion current density and at higher overpotentials was examined. The average current efficiencies for hydrogen evolution reaction are determined by a measurement of the quantity of evolved hydrogen and the overall electrodeposition current as a function of electrodeposition time, while morphologies of copper deposits are examined by the use of the scanning electron microscopy (SEM) technique. It is found that the open and porous structures of copper deposits (denoted and as honeycomb - like copper structures), suitable for electrodes in electrochemical devices such as fuel cells and chemical sensors, were reached by electrodeposition processes from solutions with the lower concentrations of $\mathrm{Cu}$ (II) ions $\left(0.15 \mathrm{M} \mathrm{CuSO}_{4}\right.$ and less in $0.50 \mathrm{M} \mathrm{H}_{2} \mathrm{SO}_{4}$ ) at overpotentials outside the plateau of the limiting diffusion current density at which the quantity of evolved hydrogen was enough to change hydrodynamic conditions in the near - electrode layer. The main characteristics of these copper structures were craters or holes formed primarily due to the attachment hydrogen bubbles with agglomerates of copper grains between them.
\end{abstract}


Keywords: Electrodeposition; Copper; Hydrogen evolution; Sensors; Scanning electron microscope (SEM).

\section{Introduction}

Electrodeposition of copper at overpotentials and current densities on the plateau of the limiting diffusion current density has been the subject of much research and the results of these investigations have been summarised [1-5]. It can be seen from these investigations that dendritic forms were a main characteristic of electrodeposition processes at these overpotentials and current densities. On the other hand, electrodeposition processes at very high current densities and overpotentials outside the plateau of the limiting diffusion current density are only investigated from point of view of a formation of powders $[1,2,4,5]$. Copper adherent deposits formed in the initial stage of electrodeposition at high current densities and overpotentials are insufficiently investigated. Investigations of such deposits formed at high current densities whereby open and very porous structures with extremely high surface areas are obtained were initiated recently [6]. The open and porous copper structures, denoted as honeycomb-like structures, are also obtained by potentiostatic electrodeposition at high overpotentials [7-9]. These structures were similar to those obtained at high current densities. The formation of these structures and the initial stage in the formation of copper powders was caused in both cases by a vigorous evolution of hydrogen.

Copper deposits obtained at high current densities and overpotentials are very important from a technological point of view. It has been stated that the open and porous structures of copper deposits obtained at high current densities were ideally suited for use as electrodes in electrochemical devices such as fuel cells, batteries and chemical sensors [6], while the extremely high surface area is relevant for evaluating some electrochemical reactions. For example, it was known that copper shows a high activity for the nitrate ion reduction [10] as well as for the reaction in which nitrate is reduced to ammonia in high yield in aqueous acidic perchlorate and sulphate media [11].

However, in spite of numerous investigations of electrodeposition processes at high overpotentials and current densities [1-5], there is no data considering the effect of hydrogen evolution on the morphology of the electrodeposited copper at high overpotentials. Having in mind a potential high technology significance of copper deposits obtained at high overpotentials, it is necessary to better recognize the effect of this process on electrodeposition of copper under these conditions. For that reason, the aim of this paper it will be to examine the effect of this process on copper electrodeposition at overpotentials on the plateau of the limiting diffusion current density or higher ones. This investigation will be done through the analysis of the effect of different concentrations of copper(II) ions on the hydrogen evolution reaction, and consequently, the morphology of copper deposits.

\section{Experimental}

Copper was potentiostatically deposited from the following solutions:

$$
\text { 0.075 } \mathrm{M} \mathrm{CuSO}_{4}+0.50 \mathrm{M} \mathrm{H}_{2} \mathrm{SO}_{4} \text { (solution (I)), }
$$


(b) $\quad 0.30 \mathrm{M} \mathrm{CuSO}_{4}+0.50 \mathrm{M} \mathrm{H}_{2} \mathrm{SO}_{4}$ (solution (II)) and

(c) $\quad 0.60 \mathrm{M} \mathrm{CuSO}_{4}+0.50 \mathrm{M} \mathrm{H}_{2} \mathrm{SO}_{4}$ (solution (III)).

Electrodepositions were performed in an open cell and at a temperature of $18.0 \pm 1.0{ }^{\circ} \mathrm{C}$. Doubly distilled water and analytical grade chemicals were used for the preparation of solutions for electrodeposition of copper. Reference and counter electrodes were of a pure copper. Copper electrodepositions onto cylindrical copper cathodes were performed at overpotentials of 550, 650 and 800 $\mathrm{mV}$. The cathodes were prepared in the following way: cylindrical copper electrodes were first covered with a thin copper film by a 2 min electrodeposition at an appropriate overpotential using the same copper plating solution which is later used for electrodeposition at the desired overpotential. The overpotentials at which copper was electrodeposited for 2 min were: $250 \mathrm{mV}$ for solution (I), $350 \mathrm{mV}$ for solution (II) and $400 \mathrm{mV}$ for solution (III). This way of preparing of copper cathodes was used in order to obtain a uniform copper surface before electrodeposition at the desired overpotentials.

SEM microphotographs corresponding to morphologies of copper deposits electrodeposited with quantities of the electricity of 10.0 and $20.0 \mathrm{mAhcm}^{-2}$ were obtained with a model JOEL T20 scanning electron microscope (SEM).

The average current efficiency of hydrogen evolution was determined in the following way: in a time $t$, the current of electrodeposition $I$ and the volume of evolved hydrogen $V\left(\mathrm{H}_{2}\right)$ are measured. After a graphical integration $I-t$, the average current efficiency for hydrogen evolution $\eta_{\mathrm{I}}$ av $\left(\mathrm{H}_{2}\right)$ is determined according to Eq. (1):

$$
\eta_{\mathrm{I}, \mathrm{av}}\left(\mathrm{H}_{2}\right)=\frac{V\left(\mathrm{H}_{2}\right)}{\mu\left(\mathrm{H}_{2}\right) \int_{0}^{t} I \mathrm{~d} t}
$$

where:

$$
\mu\left(\mathrm{H}_{2}\right)=\frac{\mathrm{V}}{\mathrm{nF}}=\frac{22400 \mathrm{~cm}^{3}}{2 \times 26.8 \mathrm{Ah}}=418 \frac{\mathrm{cm}^{3}}{\mathrm{Ah}}
$$

and $n F$ is the number of Faradays per mole of consumed ions and $V$ is molar volume of gas under normal conditions (i.e. $22400 \mathrm{~cm}^{3}$ ).

The experimental procedure for the determination of the average current efficiency of hydrogen evolution is given in [7].

\section{Results and Discussion}

3.1. Polarization measurements and the determination of the average current efficiencies of the hydrogen evolution reaction

Figure 1 shows the polarization curves for the copper electrodeposition from $0.075 \mathrm{M} \mathrm{CuSO}_{4}$ in 0.50 $\mathrm{M} \mathrm{H}_{2} \mathrm{SO}_{4}$ (solution (I)), $0.30 \mathrm{M} \mathrm{CuSO}_{4}$ in $0.50 \mathrm{M} \mathrm{H}_{2} \mathrm{SO}_{4}$ (solution (II)) and $0.60 \mathrm{M} \mathrm{CuSO}_{4}$ in $0.50 \mathrm{M}$ $\mathrm{H}_{2} \mathrm{SO}_{4}$ (solution (III)). The beginning of the plateau of the limiting diffusion current density is determined as the intersect of straight lines joining currents in mixed activation - diffusion and diffusion control of electrodeposition, as shown in the figure. The end of this plateau is determined as the overpotential at 
which current starts to grow with the increasing overpotential. The range of overpotentials on the plateau of the limiting diffusion current density determined in this way is given in Table 1 . The open circuit potentials of copper electrodes in solutions (I), (II) and (III) are also given in Table 1. From this data it can be seen that an increase of the concentration of $\mathrm{Cu}$ (II) ions in plating solutions leads to a corresponding decrease of the length of the plateau of the limiting diffusion current density.

Figure 1. Polarization curves for the cathodic process of copper deposition from: $0.075 \mathrm{M}$ $\mathrm{CuSO}_{4}+0.50 \mathrm{M} \mathrm{H}_{2} \mathrm{SO}_{4}$ (solution (I)), $0.30 \mathrm{M} \mathrm{CuSO}_{4}+0.50 \mathrm{M} \mathrm{H}_{2} \mathrm{SO}_{4}$ (solution (II)) and $0.60 \mathrm{M} \mathrm{CuSO}_{4}+0.50 \mathrm{M} \mathrm{H}_{2} \mathrm{SO}_{4}$ (solution (III)).

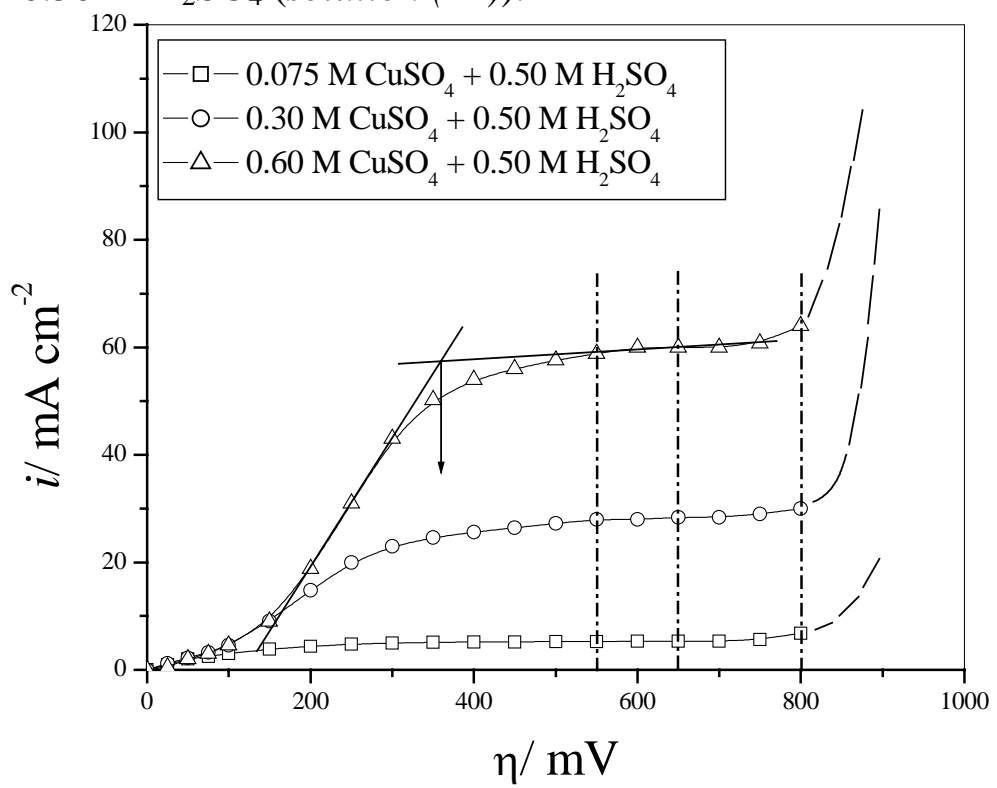

The effect of hydrogen evolution on copper electrodeposition was examined at overpotentials of 550, 650 and $800 \mathrm{mV}$. For all examined solutions, overpotentials of 550 and $650 \mathrm{mV}$ corresponded to the plateau of the limiting diffusion current density, while an overpotential of $800 \mathrm{mV}$ was about $50 \mathrm{mV}$ outside the plateau of the limiting diffusion current density (Figure 1 and Table 1).

Figure 2 shows the dependencies between electrodeposition currents and volumes of evolved hydrogen on electrodeposition time obtained at overpotentials of 550, 650 and $800 \mathrm{mV}$ from solutions (I), (II) and (III).

Table 1. The range of overpotentials belonging to the plateau of the limiting diffusion current density $(\Delta \eta)$ for solutions (I), (II) and (III) and the open circuit potentials of copper electrode in solutions (I), (II) and (III).

\begin{tabular}{|l|c|c|}
\hline Copper electrodeposition solution & $\Delta \eta / \mathbf{m V}$ & Open circuit potentials/ mV \\
\hline $0.075 \mathrm{M} \mathrm{CuSO}_{4}$ in $0.50 \mathrm{M} \mathrm{H}_{2} \mathrm{SO}_{4}$ & $140-750$ & 296 \\
\hline $0.30 \mathrm{M} \mathrm{CuSO}_{4}$ in $0.50 \mathrm{M} \mathrm{H}_{2} \mathrm{SO}_{4}$ & $280-750$ & 312 \\
\hline $0.60 \mathrm{M} \mathrm{CuSO}_{4}$ in $0.50 \mathrm{M} \mathrm{H}_{2} \mathrm{SO}_{4}$ & $360-750$ & 320 \\
\hline
\end{tabular}


Figure 2. The dependencies of the overall electrodeposition current (open style) and the volume of evolved hydrogen (solid style) on the electrodeposition time for copper electrodepositions at 550, 650 and $800 \mathrm{mV}$ from solutions (I), (II) and (III).
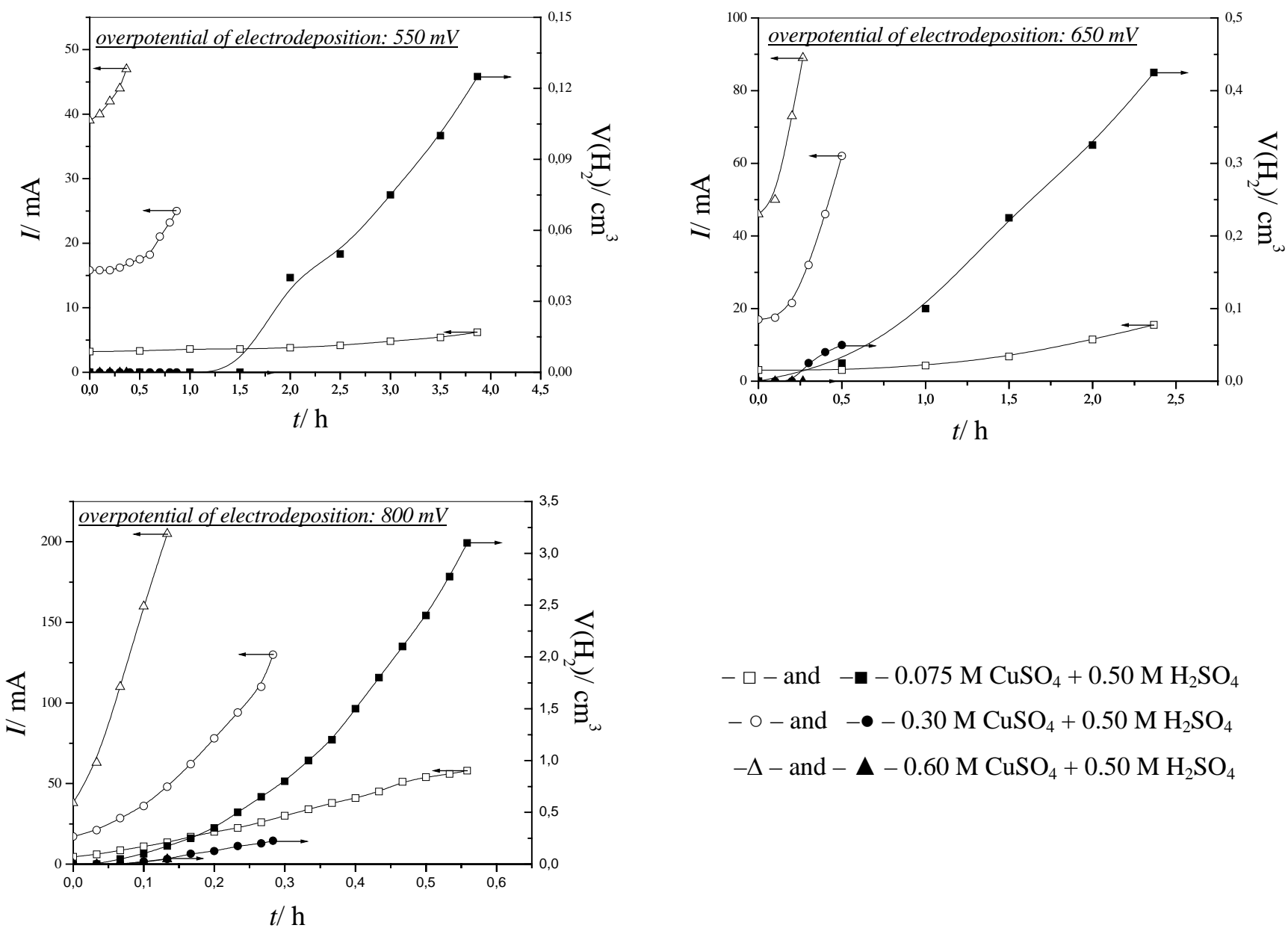

$$
\begin{gathered}
-\square-\text { and }--0.075 \mathrm{M} \mathrm{CuSO}_{4}+0.50 \mathrm{M} \mathrm{H}_{2} \mathrm{SO}_{4} \\
-\circ-\text { and }-\bullet-0.30 \mathrm{M} \mathrm{CuSO}_{4}+0.50 \mathrm{M} \mathrm{H}_{2} \mathrm{SO}_{4} \\
-\Delta-\text { and }-\boldsymbol{\Delta}-0.60 \mathrm{M} \mathrm{CuSO}_{4}+0.50 \mathrm{M} \mathrm{H}_{2} \mathrm{SO}_{4}
\end{gathered}
$$

From Figure 2 can be seen that the electrodeposition currents grew with the increasing concentration of $\mathrm{Cu}$ (II) ions during electrodeposition processes at all overpotentials. At an overpotential of $550 \mathrm{mV}$ there was hydrogen evolution only from solution (I). Electrodeposition of copper at an overpotential of $650 \mathrm{mV}$ led to hydrogen evolution not only from solution (I), but also from solution (II). The amount of evolved hydrogen was larger from solution (I) than from solution (II). Finally, copper electrodeposition processes at an overpotential of $800 \mathrm{mV}$ were accompanied by hydrogen evolution from all three solutions. A decrease of the quantity of evolved hydrogen with the increasing concentration of $\mathrm{Cu}(\mathrm{II})$ ions was observed during electrodeposition of copper at this overpotential.

The dependencies of the average current efficiencies for hydrogen evolution reactions on the quantity of passed electricity were derived from diagrams given in Figure 2 and shown in Figure 3. The summary of the obtained values of the average current efficiencies of hydrogen evolution in the dependence of concentration of $\mathrm{Cu}$ (II) ions and overpotential of electrodeposition are given in Table 2. 
Figure 3. The dependencies of the average current efficiencies for hydrogen evolution reaction on the quantity of used electricity, for copper electrodepositions at 550, 650 and 800 $\mathrm{mV}$ from solutions (I), (II) and (III).
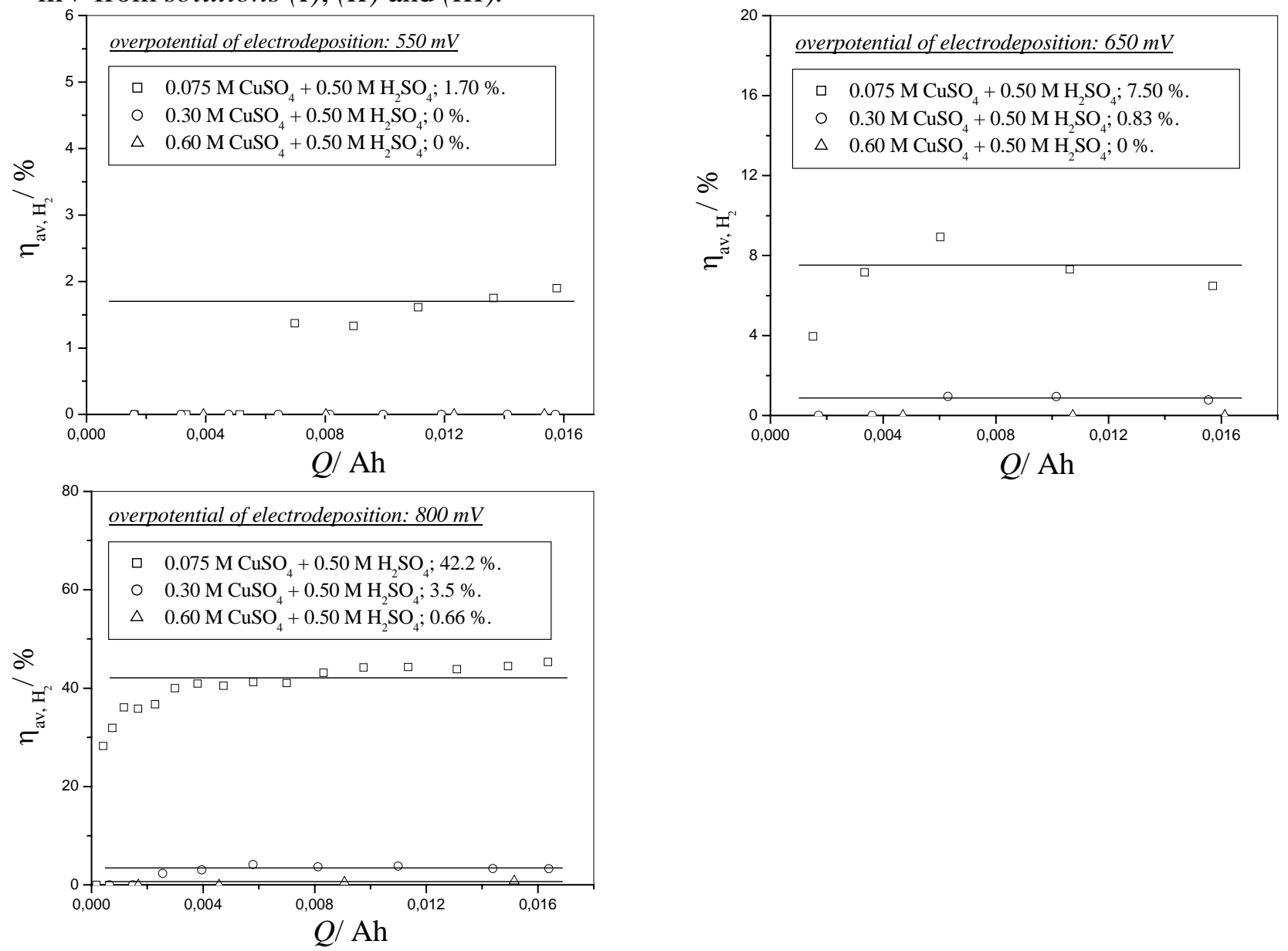

In total, the decrease of the average current efficiencies of hydrogen evolution with the increasing concentration of $\mathrm{Cu}(\mathrm{II})$ ions, as well as an increase of the average current efficiencies of hydrogen evolution with the increasing overpotential of electrodeposition were observed during these electrodeposition processes (Figure 3 and Table 2). This result can be explained by the fact that hydrogen evolution rate during copper electrodeposition from solutions containing $\mathrm{Cu}$ (II) ions in $\mathrm{H}_{2} \mathrm{SO}_{4}$ at some specified potential decreases with the increasing concentration of $\mathrm{Cu}(\mathrm{II})$ ions, while copper deposition rate, and consequently, the overall current strongly increase with the increasing concentration of $\mathrm{Cu}(\mathrm{II})$ ions. In this way, the current efficiency for hydrogen evolution reaction at specified potential decreases with the increasing concentration of $\mathrm{Cu}(\mathrm{II})$ ions. 
Table 2. The average current efficiencies of hydrogen evolution in the function of concentration of $\mathrm{Cu}(\mathrm{II})$ ions.

\begin{tabular}{|c|c|c|c|}
\hline \multirow{2}{*}{$\begin{array}{c}\text { Solution for copper } \\
\text { electrodeposition }\end{array}$} & \multicolumn{3}{|c|}{$\begin{array}{c}\text { The average current efficiencies of hydrogen } \\
\text { evolution, } \eta_{\text {av }}\left(\mathbf{H}_{\mathbf{2}}\right) \text { / \%, at overpotentials of: }\end{array}$} \\
\cline { 2 - 4 } & $\mathbf{5 5 0} \mathbf{~ m V}$ & $\mathbf{6 5 0} \mathbf{~ m V}$ & $\mathbf{8 0 0} \mathbf{~ m V}$ \\
\hline $0.075 \mathrm{M} \mathrm{CuSO}_{4}$ in $0.50 \mathrm{M} \mathrm{H}_{2} \mathrm{SO}_{4}$ & 1.7 & 7.5 & 42.2 \\
\hline $0.30 \mathrm{M} \mathrm{CuSO}_{4}$ in $0.50 \mathrm{M} \mathrm{H}_{2} \mathrm{SO}_{4}$ & 0 & 0.83 & 3.5 \\
\hline $0.60 \mathrm{M} \mathrm{CuSO}_{4}$ in $0.50 \mathrm{M} \mathrm{H}_{2} \mathrm{SO}_{4}$ & 0 & 0 & 0.66 \\
\hline
\end{tabular}

\subsection{Morphologies of copper deposits obtained at overpotentials of 550, 650 and $800 \mathrm{mV}$}

Figure 4 shows the morphologies of copper deposits electrodeposited at an overpotential of $550 \mathrm{mV}$ from solutions (I), (II) and (III) with a quantity of electricity of $10.0 \mathrm{mAhcm}^{-2}$. From Figure 4a can be seen that the copper deposit obtained from solution (I) had a cauliflower-like structure. Copper deposits obtained from solution (II) (Figure 4b) and solution (III) (Figure 4c) were globular structures.

Figure 4. Copper deposits obtained at overpotential of $550 \mathrm{mV}$. Quantity of electricity: 10.0 $\mathrm{mAhcm}^{-2}$ : (a) solution (I), (b) solution (II), (c) solution (III). Magnification: x 750.

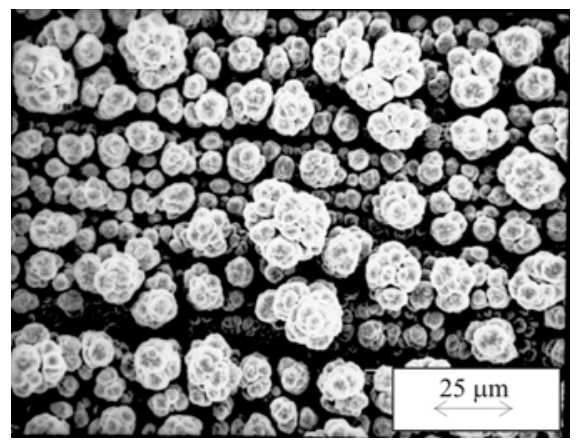

(a)

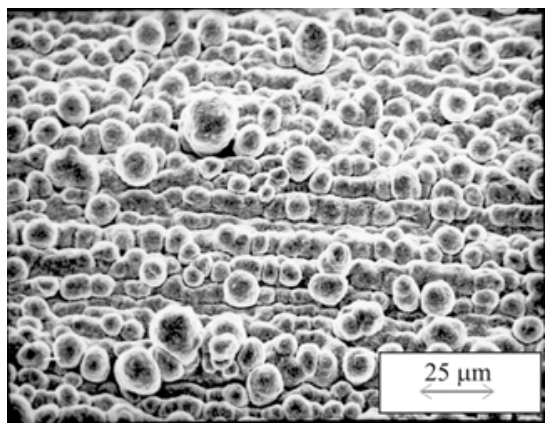

(b)

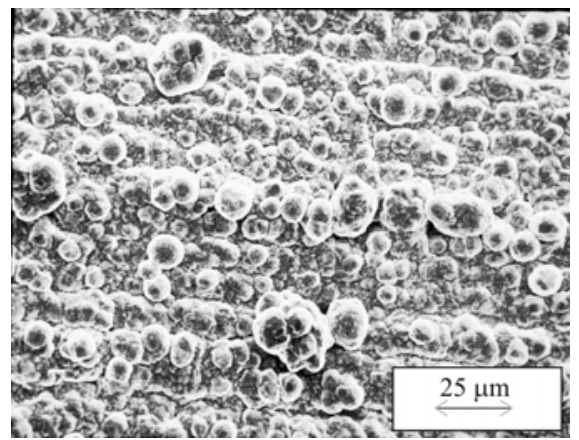

(c)

Electrodeposition of copper with twice the quantity of electricity led to a change in the morphology of copper deposits with respect to those shown in Figure 4. Figure 5 shows the morphologies of copper deposits obtained at overpotential of $550 \mathrm{mV}$ with an amount of electricity of $20.0 \mathrm{mAhcm}^{-2}$. Copper dendrites instead of cauliflower-like forms were obtained during electrodeposition of copper from solution (I) (Figure 5a). A mixture of cauliflower-like and globular forms were obtained by electrodeposition from solution (II) (Figure 5b) and solution (III) (Figure 5c).

Copper dendrites are formed from all three solutions during electrodeposition processes at an overpotential of $650 \mathrm{mV}$ with a quantity of electricity of $10.0 \mathrm{mAhcm}^{-2}$. However, from Figure 6 it can be seen that the shape of copper dendrites depends strongly on the concentration of $\mathrm{Cu}(\mathrm{II})$ ions. Very branchy copper dendrites consisting of corncob-like elements were formed from solution (I) (Figures 6a and b). Copper dendrites formed from solution (II) presented a mixture of very branchy dendritic forms (Figure 
6c) and those shaped like flowers (Figure 6d). Finally, the copper deposits obtained from solution (III) presented a mixture of flower-like (Figure 6e) and corncob-like forms (Figure 6f).

Figure 5. Copper deposits obtained at overpotential of $550 \mathrm{mV}$. Quantity of electricity: $20.0 \mathrm{mAhcm}^{-2}$ : (a) solution (I), (b) solution (II), (c) solution (III). Magnification: x 750.

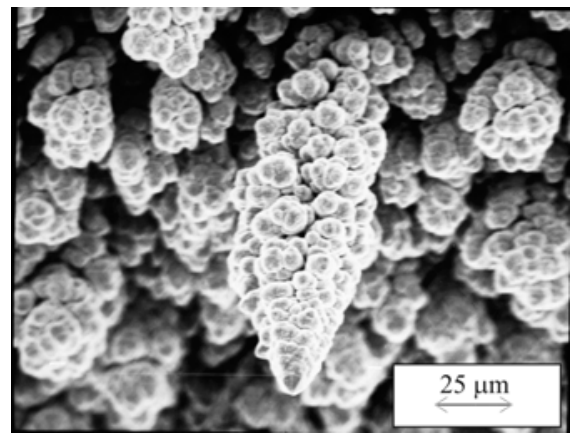

(a)

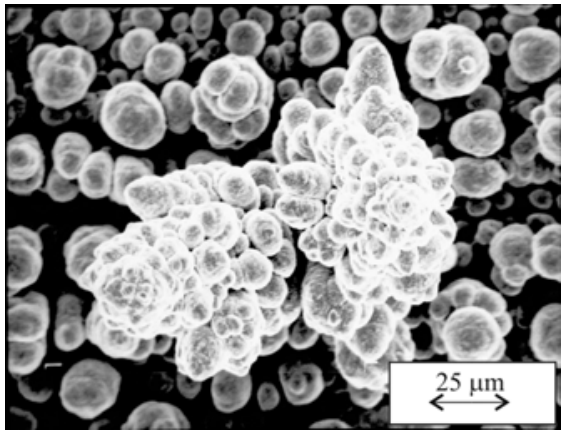

(b)

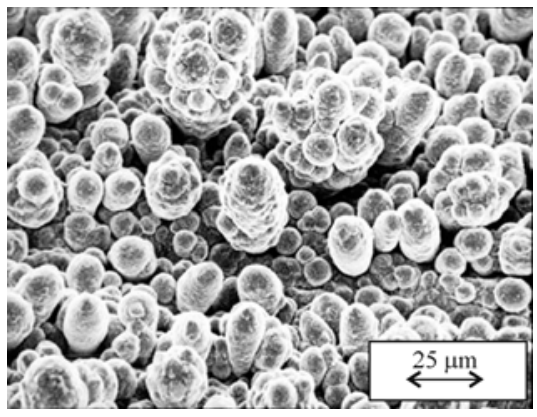

(c)

Figure 7 shows the morphologies of copper deposits obtained at an overpotential of $800 \mathrm{mV}$ with a quantity of electricity of $10.0 \mathrm{mAhcm}^{-2}$, which reveals the strong effect of concentration of $\mathrm{Cu}(\mathrm{II})$ ions on copper electrodeposition at this overpotential.

The copper deposits obtained from solution (I) had a very open and porous structure, and consisted of a large number of holes or craters formed due to the attachment of hydrogen bubbles (Figure 7a) with agglomerates of relatively small copper grains between them (Figure $7 \mathrm{~b}$ ).

The morphology of copper deposits obtained from solution (II) mainly consisted of dendritic forms but the presence of holes formed due to the attachment of hydrogen bubbles can also be seen (Figure 7c). The typical copper dendrites formed by the electrodeposition from this solution is shown in Figure 7d.

Finally, only dendritic copper forms are obtained from solution (III) (Figures 7e and f). These dendritic forms were more branchy structures than those formed from the same solution by the electrodeposition at the overpotential of $650 \mathrm{mV}$ and with the same quantity of the electricity (cf. Figures 6e and f).

The careful analysis of the morphologies of copper deposits shown in Figures $4-7$ indicated that an increase in the concentration of $\mathrm{Cu}$ (II) ions led to a shift of the formation of characteristic morphological shapes of copper deposits towards higher electrodeposition overpotentials by about 100-150 mV. For example, copper dendrites formed at $800 \mathrm{mV}$ from solution (III) (Figures 7e and f) were very similar to those obtained at $650 \mathrm{mV}$ from solutions (I) and (II) (Figures $6 \mathrm{a}-\mathrm{c}$ ). The globular forms obtained from solutions (II) and (III) (Figures $4 \mathrm{~b}$ and c) were very similar to ones obtained from $0.15 \mathrm{M} \mathrm{CuSO}_{4}$ in 0.50 $\mathrm{M} \mathrm{H}_{2} \mathrm{SO}_{4}$ at an overpotential of $450 \mathrm{mV}$ [7]. It is well known that cauliflower forms are characteristic of electrodeposition at overpotentials lower than the critical overpotential of dendritic growth initiation [1]. The different shapes of copper dendrites formed at the overpotential of $650 \mathrm{mV}$ from solutions with different concentrations of $\mathrm{Cu}(\mathrm{II})$ ions (Figure 6) also pointed out the strong effect of concentration of $\mathrm{Cu}(\mathrm{II})$ ions on electrodeposition of copper at the overpotential of $650 \mathrm{mV}$. 
Figure 6. Copper deposits obtained at overpotential of $650 \mathrm{mV}$. Quantity of electricity: 10.0 mAhcm $^{-2}$. (a) and (b): solution (I). Magnification: (a) x 750, (b) x 2000; (c) and (d): solution (II). Magnification: (c) x 2000, (d) x 750; (e) and (f): solution (III). Magnification: (e) x 750, (f) $\mathrm{x} 2000$.

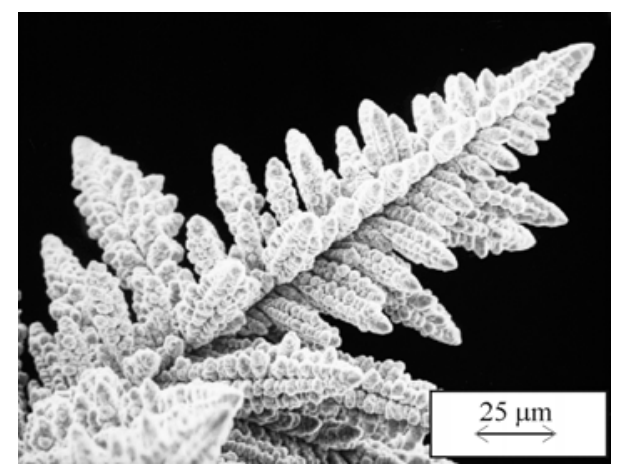

(a)

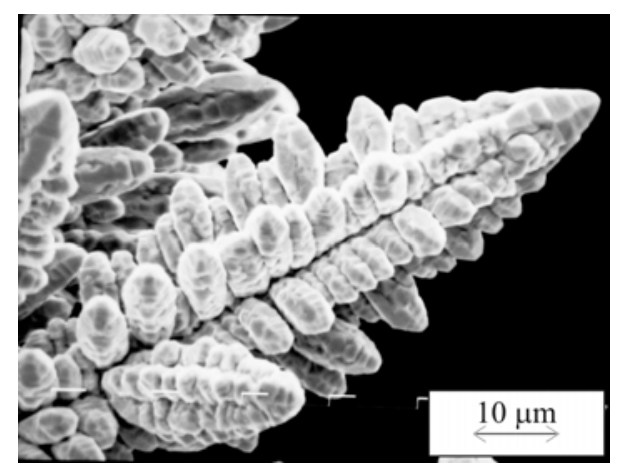

(c)

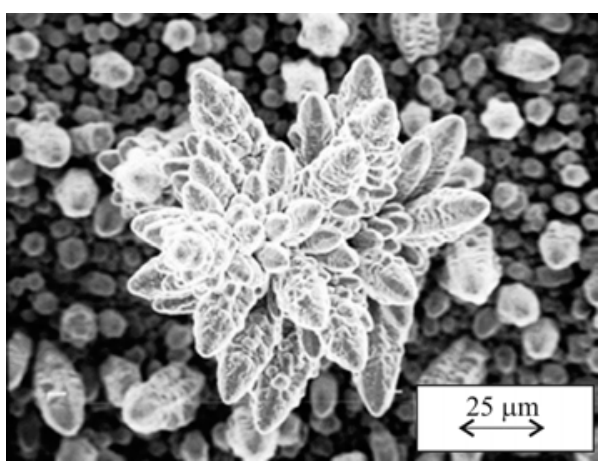

(e)

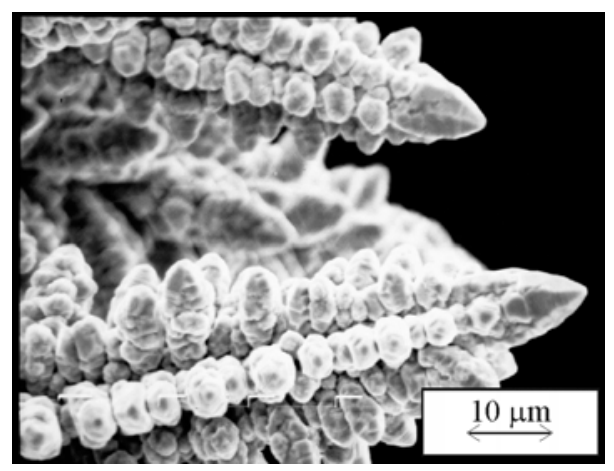

(b)

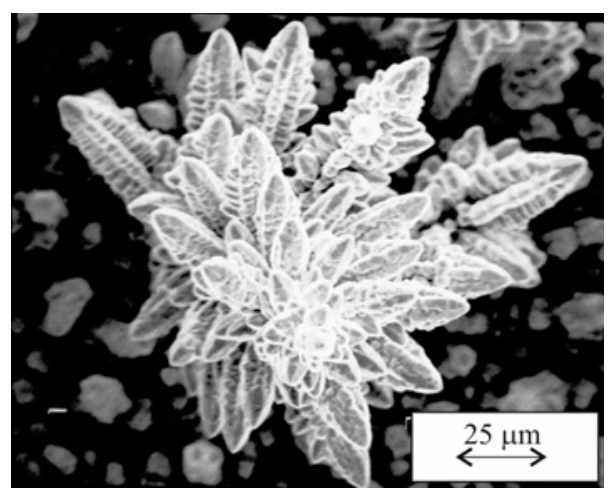

(d)

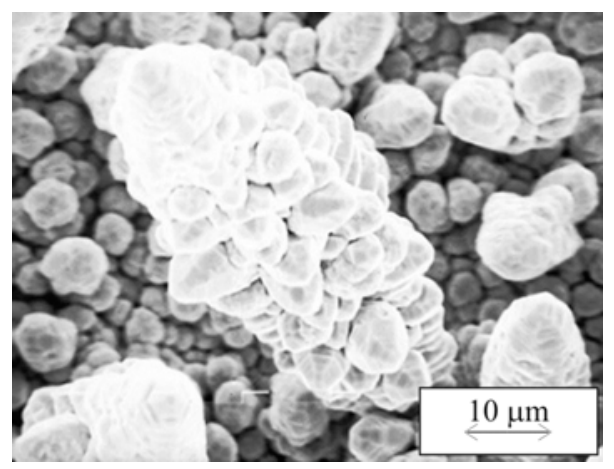

(f) 
Figure 7. Copper deposits obtained at overpotential of $800 \mathrm{mV}$. Quantity of electricity: 10.0 $\mathrm{mAhcm}^{-2}$. (a) and (b): solution (I). Magnification: (a) x 150, (b) x 5000; (c) and (d): solution (II). Magnification: (c) x 150, (d) x 750; (e) and (f): solution (III). Magnification: (e) x 150, (f) $\times 750$.

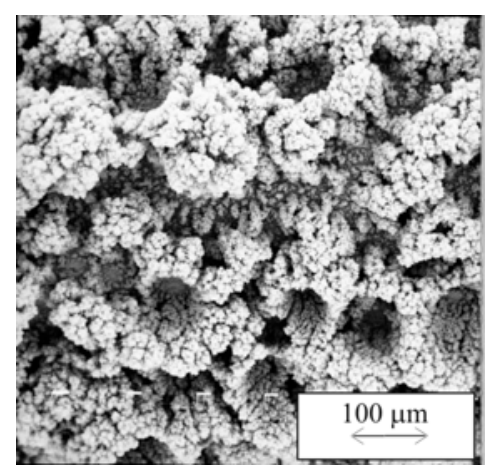

(a)

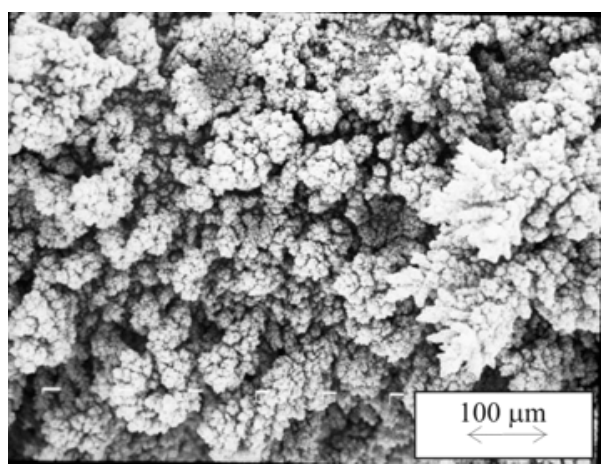

(c)

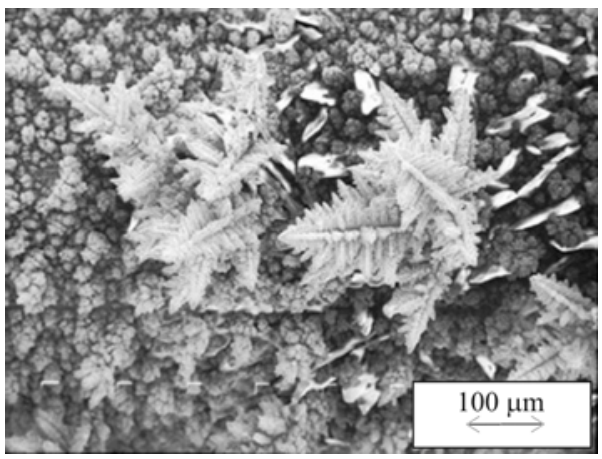

(e)

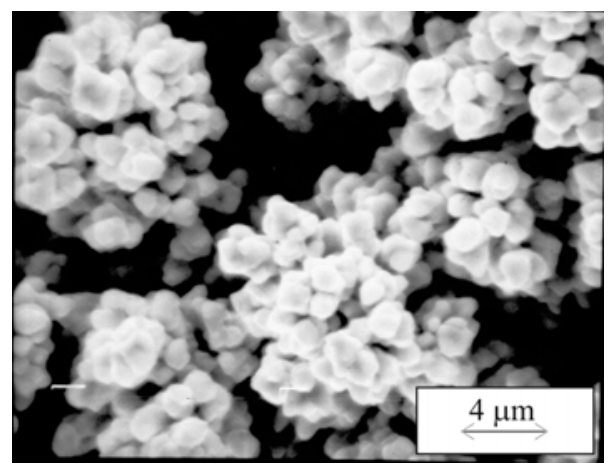

(b)

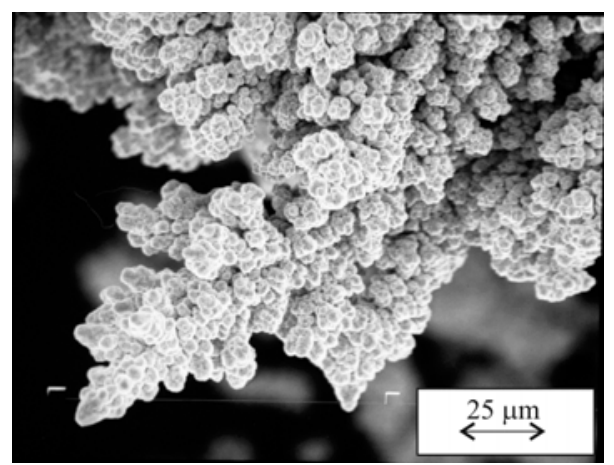

(d)

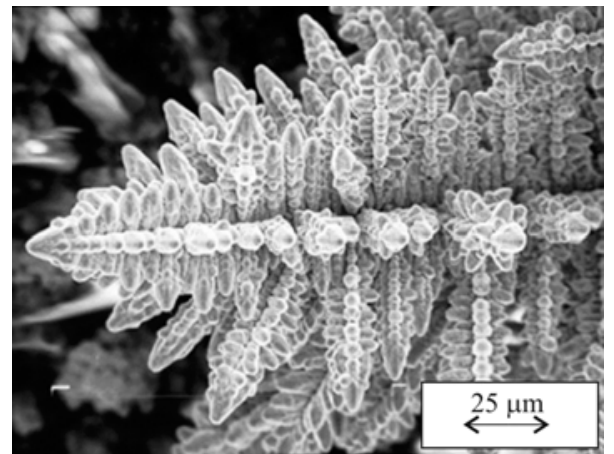

(f)

\subsection{General discussion of the results obtained}

The strong effect of the concentration of $\mathrm{Cu}(\mathrm{II})$ ions on the electrodeposition of copper at high overpotentials can be explained in terms of the minimum overpotential for the initiation of dendritic growth, in the following way:

The minimum overpotential at which dendritic growth is possible, $\eta_{I}$, is given by Equation (3) [1]: 


$$
\eta \geq \eta_{\mathrm{i}}=\frac{\mathrm{b}_{\mathrm{c}}}{2.3} \ln \frac{i_{\mathrm{L}}}{i_{0}}
$$

where $\eta$ is the overpotential, $b_{\mathrm{c}}$ the cathodic Tafel slope, $i_{\mathrm{L}}$ is the limiting diffusion current density and $i_{\mathrm{o}}$ is the exchange current density for the deposition process.

Figure 8 shows the dependence of logarithm of the limiting diffusion current density, $i_{\mathrm{L}}$ on the logarithm of the concentration of $\mathrm{Cu}(\mathrm{II})$ ions. From the obtained values of the slope and the intercept at the ordinate, it follows that the dependence of the limiting diffusion current density on the concentration of $\mathrm{Cu}(\mathrm{II})$ ions is given by $i_{\mathrm{L}}=0.32 c_{\mathrm{o}}{ }^{1.18}$. On the basis of the slope value (1.18) it can be concluded that it is possible to apply Levich`s dependence of the limiting diffusion current density on the concentration of metal ions [12].

According to Levich, in metal electrodeposition under natural convection, $i_{\mathrm{L}}$ varies with concentration as

$$
i_{\mathrm{L}} \sim c_{\mathrm{o}}{ }^{1.25}
$$

where $c_{0}$ is concentration of $\mathrm{Cu}$ (II) ions.

This relation is valid under proper isothermal conditions [13], when the temperatures of the thermostated solutions (with a free surface) and of the surrounding air are equal.

On the other hand, for copper electrodeposition from acid sulphate solutions the following expression is valid [14]:

$$
i_{0} \sim c_{0}{ }^{0.75}
$$

and $b_{c}=120 \mathrm{mV} /$ dec.

Substitution of $i_{0}$ and $i_{\mathrm{L}}$ from Eqs. (4) and (5) in Eq. (3) and further rearrangement gives that minimum overpotential for the initiation of dendritic growth depends on concentration of $\mathrm{Cu}(\mathrm{II})$ ions according to:

$$
\eta_{\mathrm{i}} \cong \mathrm{const}+60 \log c_{\mathrm{o}}
$$

From this relation it can be easily seen how the increase of concentration of $\mathrm{Cu}(\mathrm{II})$ ions affects the formation of the copper deposit morphologies considered in this paper. According to this relation, the increase of concentration of $\mathrm{Cu}(\mathrm{II})$ ions increases the minimum overpotential for the initiation of dendritic growth. In our case, we can see that copper dendrites are formed by the electrodeposition at the overpotential of $550 \mathrm{mV}$ with a quantity of the electricity of $20.0 \mathrm{mAhcm}^{-2}$ only from solution (I). Electrodepositions from solutions (II) and (III) with the same quantity of the electricity did not lead to the formation of dendritic forms at this overpotential. On the other hand, the difference in the shape of copper dendrites formed at $650 \mathrm{mV}$ pointed out that the minimum overpotential for the initiation of dendritic growth was lower from solution (I) than from solutions (II) and (III).

On the basis of the values of the average current efficiencies of hydrogen evolution reactions and the morphologies of copper deposits shown in Figures 4-7, the correlation between the quantity of evolved hydrogen and the formation of different morphological forms of copper deposits can be made.

Copper dendrites were the main morphological form during electrodeposition processes which were accompanied by average current efficiencies of hydrogen evolution up to $7.5 \%$. The quantities of evolved 
hydrogen which corresponded to the average current efficiencies up to $7.5 \%$ were insufficient to change the hydrodynamic conditions in the near-electrode layer, and to disarrange the diffusion layer thickness of the macroelectrode. The dominant processes are diffusion of ions from bulk solution to the electrode surface [1].

Figure 8. The dependence of logarithm of the limiting diffusion current density, $i_{\mathrm{L}}$ on logarithm of concentration of $\mathrm{Cu}$ (II) ions.

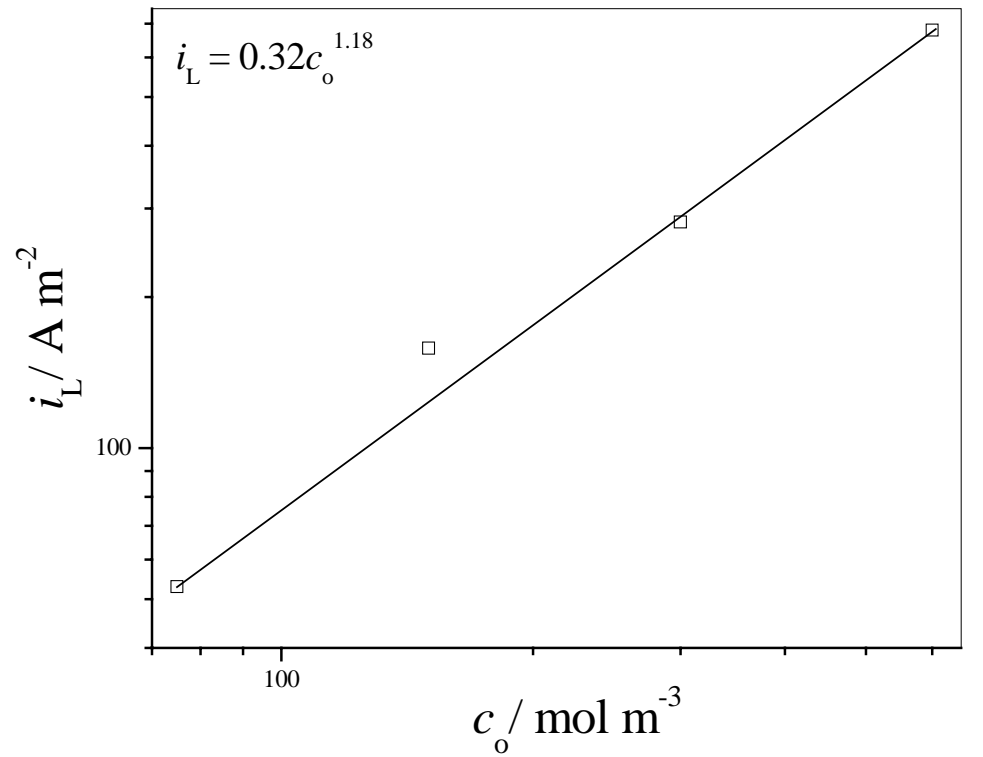

On the other hand, craters or holes formed due to the attachment of hydrogen bubbles with copper grain agglomerates between them are obtained when the copper electrodeposition process was accompanied by an average current efficiency of hydrogen evolution of $42.2 \%$ (Figures $7 \mathrm{a}$ and b). The hydrogen evolution was vigorous enough to cause a stirring of the solution, thus decreasing the cathode diffusion layer thickness and increasing the limiting diffusion current density, and consequently, leading to a change of hydrodynamic conditions in the near-electrode layer. This copper structure presented the typical honeycomb-like structure. The formation of this structure was recently explained by the concept of "effective overpotential" [7]. According to this concept, when hydrogen evolution is vigorous enough to change the hydrodynamic conditions in the near-electrode layer, the electrodeposition process takes place at an overpotential which is effectively lower than the specified one. For that reason, this overpotential is denoted as the "effective overpotential" of the electrodeposition process. Because of a change of hydrodynamic conditions caused by a vigorous hydrogen evolution the morphologies of deposits become, at a macro level, similar to ones obtained at some lower overpotentials where the hydrogen evolution does not exist. In our case, the morphology of the copper deposit shown in Figure $7 \mathrm{~b}$ (cauliflower forms) is similar to that obtained at some lower overpotentials before dendritic growth initiation (Figure 4a). The honeycomb-like structures were obtained and electrodeposition processes observed from $0.15 \mathrm{M} \mathrm{CuSO}_{4}$ in $0.50 \mathrm{M} \mathrm{H}_{2} \mathrm{SO}_{4}$ at overpotentials of 800 and $1000 \mathrm{mV}$, with average current efficiencies of hydrogen evolution of 10.8 and $30.0 \%$, respectively [7]. In this case the critical value of the average current efficiency of hydrogen evolution which leads to the change of hydrodynamic 
conditions in near-electrode layer and the formation of honeycomb-like structure was estimated to be about $10.0 \%$.

However, it is obvious that due to their very open and porous structure, the honeycomb-like copper deposits fulfilled the conditions to be considered as possible electrodes in electrochemical devices such as solid oxide fuel cells and solid-state gas sensors. Hence, the critical conditions which must be fulfilled in order to obtain copper deposits suitable for these purposes by potentiostatic electrodeposition are: electrodeposition from acid copper sulphate solutions with lower concentrations of $\mathrm{Cu}$ (II) ions (0.15 M $\mathrm{CuSO}_{4}$ and less for a concentration of supporting electrolyte of $0.50 \mathrm{M} \mathrm{H}_{2} \mathrm{SO}_{4}$ ), at overpotentials outside the plateau of the limiting diffusion current density at which the quantity of evolved hydrogen is enough to change hydrodynamic conditions in near-electrode layer. This quantity of evolved hydrogen corresponded to the average current efficiencies of hydrogen evolution above $10.0 \%$. Also, we note that the number of craters or holes increased with the quantity of evolved hydrogen, as can be seen from Figure 9 which shows the dependence of the number of holes or craters formed due to the attachment hydrogen bubbles on the average current efficiencies for hydrogen evolution.

Figure 9 includes the value of the average current efficiency of hydrogen evolution of $68.7 \%$ obtained from solution (I) at overpotential of $1000 \mathrm{mV}$ [15]. This dependence of the number of holes per $\mathrm{mm}^{2}$ surface area of copper electrode on the average current efficiency of hydrogen evolution clearly points out the fact that the more intense the hydrogen evolution, the more porous a copper structure is formed. Also, from Figure 9 it can be seen that more porous structures (i.e. structures with larger numbers of holes formed by evolved hydrogen) are obtained by electrodeposition of copper from solutions with the lower concentrations of $\mathrm{Cu}(\mathrm{II})$ ions $\left(0.075 \mathrm{M} \mathrm{CuSO}_{4}\right.$ in $0.50 \mathrm{M} \mathrm{H}_{2} \mathrm{SO}_{4}$ with respect to copper electrodeposited from $0.15 \mathrm{M} \mathrm{CuSO}_{4}$ in $0.50 \mathrm{M} \mathrm{H}_{2} \mathrm{SO}_{4}$ ).

Figure 9. The dependence of the number of craters formed due to the attachment of hydrogen bubbles per $\mathrm{mm}^{2}$ surface area of copper electrode on the average current efficiency of hydrogen evolution.

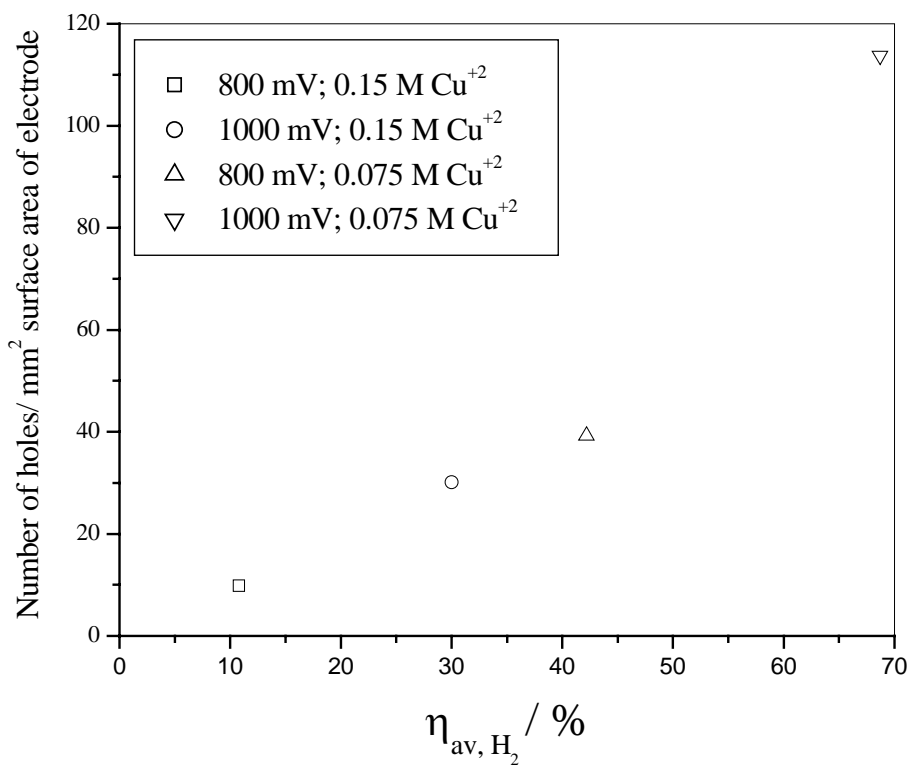




\section{Conclusions}

Electrodeposition of copper from $0.075 \mathrm{M}, 0.30 \mathrm{M}$ and $0.60 \mathrm{M} \mathrm{CuSO}_{4}$ in $0.50 \mathrm{M} \mathrm{H}_{2} \mathrm{SO}_{4}$, at overpotentials of 550, 650 and $800 \mathrm{mV}$ was examined by the determination of the average current efficiency of hydrogen evolution and the SEM technique. Dendritic forms were the main characteristic of electrodeposition processes which were accompanied by an average current efficiency of hydrogen evolution up to $7.5 \%$. The quantities of evolved hydrogen which corresponded to the average current efficiencies of hydrogen evolution up to $7.5 \%$ were insufficient to change hydrodynamic conditions in the near-electrode layer.

Very open and porous honeycomb-like copper structures suitable for use as electrodes for solid-state gas sensors as well as for other electrochemical devices are obtained by electrodeposition processes which are accompanied by an average current efficiency of hydrogen evolution above $10.0 \%$. The main characteristics of these structures were craters or holes formed due to the attachment of hydrogen bubbles with agglomerates of copper grains between them. These structures are formed by electrodeposition at overpotentials outside the plateau of the limiting diffusion current density from solutions with lower concentrations of $\mathrm{Cu}(\mathrm{II})$ ions $\left(0.15 \mathrm{M} \mathrm{CuSO}_{4}\right.$ and less in $0.50 \mathrm{M} \mathrm{H}_{2} \mathrm{SO}_{4}$ ). The quantities of evolved hydrogen which led to the formation of these structures were enough to change the hydrodynamic conditions in the near-electrode layer.

\section{Acknowledgements}

This work was supported by the Ministry of Science and Environmental Protection of the Republic of Serbia under the Research Project "Deposition of ultrafine powders of metals and alloys and nanostructured surfaces by electrochemical techniques” (No. 142032G).

\section{References}

1. Popov, K. I.; Djokic, S. S.; Grgur, B. N. Fundamental Aspects of Electrometallurgy; Kluwer Academic/Plenum Publishers: New York, 2002, and references therein.

2. Popov, K. I.; Pavlovic, M. G. Electrodeposition of Metal Powders with Controlled Grain Size and Morphology. In Modern Aspects of Electrochemistry; Vol. 24, White, R.W.; Bockris, J. O’M.; Conway, B. E., Eds.; Plenum Press: New York, 1993; pp. 299-391.

3. Popov, K. I.; Krstajic, N. V.; Cekerevac, M. I. The Mechanism of Formation of Coarse and Disperse Electrodeposits. In Modern Aspects of Electrochemistry; White, R. E.; Conway B. E.; Bockris, J. O’M., Eds.; Plenum Press: New York, 1996; Vol. 30, pp. 261-311.

4. Calusaru, A. Electrodeposition of Metal Powders; Elsevier: Amsterdam-Oxford-New York, 1979.

5. Pavlovic, M. G.; Popov, K. I. Metal powder production by electrolysis, in Electrochemistry Encyclopedia; http://electrochem.cwru.edu/ed/encycl/.

6. Shin, Heon - Cheol; Dong, Jian; Liu, M. Nanoporous Structures Prepared by an Electrochemical Deposition Process. Adv. Mat. 2003, 15, 1610-1614. 
7. Nikolic, N. D.; Popov, K. I.; Pavlovic, Lj. J.; Pavlovic, M. G. The effect of hydrogen codeposition on the morphology of copper electrodeposits. I. The concept of effective overpotential. J. Electroanal. Chem. 2006, 588, 88-98.

8. Nikolic, N. D.; Popov, K. I.; Pavlovic, Lj. J.; Pavlovic, M. G. Morphologies of copper deposits obtained by the electrodeposition at high overpotentials. Surf. Coat. Technol. 2006, 201, 560-566.

9. Nikolic, N. D.; Popov, K. I.; Pavlovic, Lj. J.; Pavlovic, M. G. Phenomenology of a formation of a honeycomb - like structure during copper electrodeposition. J. Solid State Electrochem. In press.

10. Dima, G. E.; de Vooys, A. C. A.; Koper, M. T. M. Electrocatalytic reduction of nitrate at low concentration on coinage and transition - metal electrodes in acid solutions. J. Electroanal. Chem. 2003, 554-555, 15-23.

11. Pletcher, D.; Poorbedi, Z. The reduction of nitrate at a copper cathode in aqueous acid. Electrochim. Acta 1979, 24, 1253-1256.

12. Levich, V. G.; Physicochemical Hydrodynamics; Prentice - Hall, Inc: Englewood Cliffs, NJ, 1962; Chapter 2.

13. Blagojevic, N. S.; Maksimovic, M. D.; Popov, K. I. Approximate Analysis of the Total Flux on the Surface of Vertical Objects in Liquids under Natural Convection. Chem. Eng. J. 1978, 16, 35-39.

14. Enyo, M. PhD thesis; University of Pennsylvania, 1960.

15. Nikolic, N. D.; Popov, K. I.; Pavlovic, Lj. J.; Pavlovic, M. G. The effect of concentration of copper (II) ions on copper electrodeposition processes at high overpotential. J. Electrochem. Soc. Unpublished results.

(C) 2007 by MDPI (http://www.mdpi.org). Reproduction is permitted for noncommercial purposes. 